\title{
Inadequate Self-Care Behaviors among Malaysian Diabetic Patients: The Need for Action by Hospital Pharmacists
}

\author{
Ju-Ying Ang ${ }^{1 *}$, Jie-Shi Leo ${ }^{2}$, Doris George ${ }^{2}$, Huan-Keat Chan ${ }^{3}$ \\ ${ }^{1}$ Clinical Research Centre, Hospital Raja Permaisuri Bainun, Jalan Raja Asman Shah, 30450 Ipoh, Perak, MALAYSIA. \\ ${ }^{2}$ Department of Pharmacy, Hospital Raja Permaisuri Bainun, Jalan Raja Asman Shah, 30450 Ipoh, Perak, MALAYSIA. \\ ${ }^{3}$ Clinical Research Center, Sultanah Bahiyah Hospital, 05460 Alor Setar, Kedah, MALAYSIA.
}

Received: 23 February 2018;

Accepted: 11 May 2018

*Correspondence to:

Ju-Ying Ang, B.Pharm,

Clinical Research Centre, Aras 4, Kompleks Rawatan Harian, Hospital Raja Permaisuri Bainun, Jalan Raja Asman Shah, 30450 Ipoh, Perak, MALAYSIA.

Email: angjy.crcperak@gmail.com

Copyright: (1) the author(s),publisher and licensee Indian Academy of Pharmacists. This is an open-access article distributed under the terms of the Creative Commons Attribution Non-Commercial License, which permits unrestricted non-commercial use, distribution, and reproduction in any medium, provided the original work is properly cited.

\begin{abstract}
Background: Self-care behaviors have been confirmed to be strongly associated with clinical outcomes of diabetes management. Objective: To determine the prevalence and risk factors of inadequate self-care behaviors among the Malaysian patients with type two diabetes mellitus (T2DM) through screening by hospital pharmacists. Methods: A cross-sectional study was undertaken over a nine-month period at a public tertiary care center in Northern Malaysia. Self-care behaviors of 103 patients with T2DM were evaluated using the 16-item Diabetes Self-Management Questionnaire (DSMQ), and the scores were dichotomized to represent "adequate" ( $\geq 6$ out of 10 ) and "inadequate" ( $<6$ out of 10 ) self-care behaviors. The risk factors for inadequate self-care behaviors were identified using logistic regression analysis. Results: The participants recorded a mean DSMO score of $7.48 \pm 1.32$, and $16(15.5 \%)$ of them were found to have inadequate self-care behaviors. Among the four subscales assessed, the "Health-Care Use" had the highest score (8.36 \pm 1.99$)$, while the "Physical Activity" had the lowest score $(6.82 \pm 2.56)$. Patients with a duration of T2DM less than one year (OR: $12.00 ; 95 \% \mathrm{Cl}: 1.80,80.05 ; \mathrm{p}=0.010$ ) and between six to ten years (OR: $7.11 ; 95 \% \mathrm{Cl}: 1.36,37.31 ; \mathrm{p}=0.020)$ were found more likely to have inadequate self-care behaviors, as compared with those with a disease duration greater than 10 years. Conclusion: A noticeable proportion of patients with T2DM in Malaysia had inadequate self-care behaviors, and were found to be associated with the disease duration. This study suggests a more active role for hospital pharmacists in monitoring and improving the diabetes management of patients.
\end{abstract}

Key words: Malaysia, Tertiary care centers, Pharmaceutical services, Pharmacists, Self-care, Type 2 diabetes mellitus.

\section{INTRODUCTION}

Diabetes, notably type two diabetes mellitus (T2DM), is a major cause of mortality, morbidity and increasing healthcare cost worldwide. ${ }^{[1]}$ The global prevalence of diabetes has risen at an alarming rate, from 4.3\% in 1980 to $9 \%$ in 2014 in men, and from 5\% in 1980 to $7.9 \%$ in 2014 in women. ${ }^{[2]} \mathrm{A}$ similar trend was also observed in Malaysia, as the prevalence of diabetes increased steadily from $6.3 \%$ in 1986 to $14.9 \%$ in 2006, and the increasing number of diabetic patients is expected to reach approximately 2.48 million by $2030 .^{[3-4]}$ The total healthcare cost of diabetes and its complications in Malaysia is estimated to be in the range of USD 1.07 to 1.83 million annually, posing a burden, especially on the public healthcare system. ${ }^{[5]}$ Hence, there is an urgent need for a population-based strategy that prevents diabetes and delays its progression in Malaysia.

When it comes to optimizing glycemic control in diabetes, one of the most important factors is the self-care behaviors of patients. ${ }^{[6]}$ Good self-care management, including diet control, regular physical activity, self-monitoring of blood glucose, and adherence to medications, enables patients to effectively manage the disease on their own. ${ }^{[7]}$ Within this context, pharmacists were confirmed to have a positive impact on health outcomes of diabetic patients through their role in providing education on both medication and lifestyle issues. ${ }^{[8]}$ In fact, along with other health professionals, hospital pharmacists in Malaysia have long been involved in diabetes management, mainly through the Diabetes Medication Therapy Adherence Clinic (DMTAC). ${ }^{\left[{ }^{9}-10\right]}$

Nevertheless, to date, the information on the level of self-care behaviors among the Malaysian diabetic patients is still limited. Additionally, although education on medications, management of hypoglycemia and hyperglycemia, diet and exercise has been incorporated into the pharmacistoperated DMTAC, ${ }^{[9]}$ there is a lack of standardized tools to effectively and systematically evaluate the self-care behaviors of patients. Therefore, this hospital pharmacy-based study was designed to determine the prevalence of inadequate self-care behaviors among diabetic patients in Malaysia, and to determine the risk factors of inadequate self-care behaviors by using a structured questionnaire.

\section{METHODS}

This cross-sectional study was undertaken at the Raja Permaisuri Bainun Hospital, a public tertiary care center with 990-bed capacity in Northern Malaysia, ${ }^{[11]}$ from December 2015 until August 2016. The study protocol was registered with the National Medical Research Register (NMRR-151193-24276) and was reviewed and approved by the Medical Research and Ethics Committee. A convenience sample of outpatients with T2DM, who were aged 18 years or above, was recruited at the Medical Department of the 


\section{Ang, et al:: Study about Self-Care Behaviors among Diabetic Patients}

hospital. All participants were briefed on the study objectives, and a written informed consent was obtained from each of them.

The evaluation of self-care behaviors was conducted using the 16-item Diabetes Self-Management Questionnaire (DSMQ), which consists of four subscales: "Glucose Management" (five items), "Dietary Control" (four items), "Physical Activity" (three items) and "Health-Care Use" (three items). ${ }^{[12]}$ Each item was designed for patients to self-describe their self-care activity over the past eight weeks by using a four-point scale (3 - "applies to me very much"; 2 - "applies to me to a considerable degree"; 1 - "applies to me to some degree"; 0 - "does not apply to me").

For the DSMQ to be used in the current study, its English version was translated into Malay (M-DSMQ) and Simplified Chinese (SC-DSMQ) according to the methods recommended by Beaton et $a l,{ }^{[13]}$ including forward translation (by a bilingual pharmacists and a bilingual non-medical personnel each), synthesis (discrepancies dissolved by consensus between two translators), backward translation (by two bilingual pharmacists each), and expert review (a panel of research officers to ensure that the translated versions were comprehensible and conceptually as close as possible to the original version). Subsequently, the finalized M-DSMQ and SC-DSMQ were pilot-tested with 12 bilingual patients each, yielding Cronbach's $\alpha$ coefficients of 0.91 and 0.82 , respectively.

The self-reported demographic details of the participants, including age, gender, ethnicity, and educational level, were recorded using a data collection form. On the other hand, the information on their disease and treatment, including the most recent glycosylated hemoglobin (HbA1C) level, disease duration, number of medications taken, and number of co-morbidity, was obtained from the electronic medical records. Furthermore, the HbA1C levels were used to categorize the participants into "controlled" $(\leq 7.5 \%)$ or "uncontrolled" (>7.5\%) T2DM. ${ }^{[14]}$

Subsequently, the participants were given the option to use either the M-DSMQ or the SC-DSMQ. On average, each of them took 20 min to complete the questionnaire. Their responses were then transformed into a total score (DSMQ score) and four subscale scores ranging from 0 to 10 such that a higher score was indicative of better self-care behaviors. ${ }^{[12]}$ Subsequently, based on the recommendation of Schmitt et al. on the cut-off value, the DMSQ scores of the participants were dichotomized to represent "adequate" $(\geq 6)$ and "inadequate" $(<6)$ self-care behaviors ${ }^{[15]}$

Data were managed and analyzed using the Statistical Package for the Social Sciences 20.0 (IBM, New York). All the categorical variables were expressed as frequencies and percentages, whereas all the numerical variables, including the subscale and DSMQ scores, were summarized as means and standard deviations (SDs). Furthermore, the risk factors for inadequate self-care behaviors were identified using logistic regression analysis, presented with odds ratios (ORs) and 95\% confidence intervals (CIs). All the statistical tests were considered significant if $\mathrm{p}<0.05$.

Sample size was calculated by using the formula for estimating the population prevalence, with the level of confidence and precision fixed at $95 \%$ and $5 \%$, respectively. ${ }^{[16]}$ The anticipated prevalence of inadequate self-care behaviors was $6 \%$ based on a previous study reporting the self-management behaviors of patients with T2DM in China. ${ }^{[17]}$ To account for a $20 \%$ non-response rate, the required sample size was determined to be 105 .

\section{RESULTS}

A total of 120 participants completed the survey, but 17 (14.2\%) of them were excluded from the analysis due to incomplete responses. The 103 participants included had a mean (SD) age of $62.2(11.3)$ years. The majority of them were male (26.2\%), Chinese (36.9\%), and with secondary education (61.2\%). Besides, it is found that approximately half of them had been diagnosed with T2DM for more than ten years, and most reported having at least one other chronic illness $(84.5 \%)$ and taking at least four prescription medications $(81.6 \%)$. It is also noted that nearly half of the patients had uncontrolled T2DM, with a HbA1C level above 7.5\% (Table 1).

The participants recorded a mean DSMQ score of 7.48 \pm 1.32 , and $16(15.5 \%)$ of them were identified to have inadequate self-care behaviors. Among the four subscales of self-care behaviors evaluated, the "Health-Care Use" had the highest score (8.36 \pm 1.99$)$, followed by "Glucose Management" (7.61 \pm 2.56$)$,

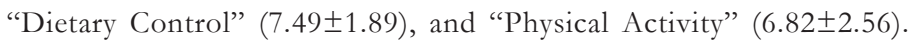
Moreover, in comparison with those with a duration of T2DM greater than ten years, the patients with a duration of T2DM less than one year (OR: 12.00; 95\%CI: 1.80, 80.05; $\mathrm{p}=0.010)$ and between six to ten years (OR: 7.11; $95 \%$ CI: $1.36,37.31 ; \mathrm{p}=0.020)$ were found more likely to have inadequate self-care behaviors. Apart from that, no other baseline characteristics of the participants were associated with self-care behaviors (Table 2).

\section{DISCUSSION}

To the best knowledge of the investigators, the current study is the first using a validated self-administered questionnaire to evaluate the self-care behaviors of patients with T2DM in Malaysia. Different from a previous study that reported a number of poor self-care practices in Malaysian diabetic patients, ${ }^{[18]}$ the different aspects of self-care behaviors of the patients were represented by a single score ranging from 0 to 10 in the current study. Therefore, by providing an objective assessment for the level of self-care behaviors of the patients, the findings could be useful for the Malaysian pharmacists, who have been actively involved in designing, implementing, improving, and

\begin{tabular}{|c|c|}
\hline Age, years, mean (SD*) & $62.19(11.30)$ \\
\hline $\begin{array}{l}\text { Gender, n (\%) } \\
\text { Male } \\
\text { Female }\end{array}$ & $\begin{array}{l}71(68.9) \\
32(31.3)\end{array}$ \\
\hline $\begin{array}{l}\text { Ethnicity, n (\%) } \\
\text { Malay } \\
\text { Chinese } \\
\text { Indian }\end{array}$ & $\begin{array}{l}27(26.2) \\
38(36.9) \\
38(36.9)\end{array}$ \\
\hline $\begin{array}{l}\text { Educational level, } \mathrm{n}(\%) \\
\text { Primary ( } 6 \text { years of elementary education) } \\
\text { Secondary (pre-university) } \\
\text { Tertiary (university and college) }\end{array}$ & $\begin{array}{l}27(26.2) \\
63(61.2) \\
13(12.6)\end{array}$ \\
\hline $\begin{array}{l}\text { Duration of } \mathrm{T}^{2} \mathrm{DM}^{\dagger} \text {, years, } \mathrm{n}(\%) \\
<1 \\
1-5 \\
6-10 \\
>10\end{array}$ & $\begin{array}{l}7(6.8) \\
32(31.1) \\
13(12.6) \\
51(49.5)\end{array}$ \\
\hline $\begin{array}{l}\text { Number of co-morbidity, } \mathrm{n}(\%) \\
0 \\
1 \\
2 \\
\geq 3\end{array}$ & $\begin{array}{l}16(15.5) \\
39(37.9) \\
32(31.1) \\
16(15.5)\end{array}$ \\
\hline $\begin{array}{l}\text { Number of medications taken, } \mathrm{n}(\%) \\
1-3 \\
4-6 \\
\geq 7\end{array}$ & $\begin{array}{l}19(18.4) \\
56(54.4) \\
28(27.2)\end{array}$ \\
\hline $\begin{array}{l}\text { Most recent } \mathrm{HbA} 1 \mathrm{C} \text { level, \%, n (\%) } \\
\leq 7.5 \\
>7.5\end{array}$ & $\begin{array}{l}57(55.3) \\
46(44.7)\end{array}$ \\
\hline
\end{tabular}

$\mathrm{SD}^{*}$, standard deviation; T2DM†, type 2 diabetes mellitus. 
Ang, et al.: Study about Self-Care Behaviors among Diabetic Patients

\begin{tabular}{|c|c|c|c|c|}
\hline Factors & Adequate & Inadequate & OR* $(95 \% \mathrm{Cl} \dagger)$ & $p$-value \\
\hline Age, years, mean (SD $\left.{ }^{\ddagger}\right)$ & $58.25(9.10)$ & $62.92(11.58)$ & $0.97(0.92,1.01)$ & 0.133 \\
\hline $\begin{array}{l}\text { Gender, } \mathbf{n}(\%) \\
\text { Female } \\
\text { Male }\end{array}$ & $\begin{array}{l}29(90.6) \\
58(81.7)\end{array}$ & $\begin{array}{l}3(9.4) \\
13(18.3)\end{array}$ & $\begin{array}{l}1 \\
2.17(0.57,8.21)\end{array}$ & $-\overline{-}$ \\
\hline $\begin{array}{l}\text { Ethnicity, } \mathbf{n}(\%) \\
\text { Indian } \\
\text { Chinese } \\
\text { Malay }\end{array}$ & $\begin{array}{l}33(86.8) \\
33(86.8) \\
21(77.8)\end{array}$ & $\begin{array}{l}5(13.2) \\
5(13.2) \\
6(22.2)\end{array}$ & $\begin{array}{l}1 \\
1.00(0.26,3.78) \\
1.89(0.51,6.97)\end{array}$ & $\begin{array}{l}- \\
>0.95 \\
0.341\end{array}$ \\
\hline $\begin{array}{l}\text { Educational level, } \mathbf{n} \text { (\%) } \\
\text { Primary } \\
\text { Secondary } \\
\text { Tertiary }\end{array}$ & $\begin{array}{l}25(92.6) \\
51(81.0) \\
11(84.6)\end{array}$ & $\begin{array}{l}2(7.4) \\
12(19.0) \\
2(15.4)\end{array}$ & $\begin{array}{l}1 \\
2.94(0.61,14.16) \\
2.27(0.28,18.27)\end{array}$ & $\begin{array}{l}- \\
0.178 \\
0.440\end{array}$ \\
\hline $\begin{array}{l}\text { Duration of T2DM }{ }^{\S} \text {, years, } \mathbf{n}(\%) \\
>10 \\
6-10 \\
1-5 \\
<1\end{array}$ & $\begin{array}{l}48(94.1) \\
9(69.2) \\
26(81.2) \\
4(57.1)\end{array}$ & $\begin{array}{l}3(5.9) \\
4(30.8) \\
6(18.8) \\
3(42.9)\end{array}$ & $\begin{array}{l}1 \\
7.11(1.36,37.31) \\
3.69(0.85,15.99) \\
12.00(1.80,80.05)\end{array}$ & $\begin{array}{l}- \\
0.020 \\
0.081 \\
0.010\end{array}$ \\
\hline $\begin{array}{l}\text { Number of co-morbidity, } \mathbf{n}(\%) \\
\geq 3 \\
2 \\
1 \\
0\end{array}$ & $\begin{array}{l}15(93.8) \\
26(81.2) \\
35(89.7) \\
11(68.8)\end{array}$ & $\begin{array}{l}1(6.2) \\
6(18.8) \\
4(10.3) \\
5(31.2)\end{array}$ & $\begin{array}{l}1 \\
3.46(0.38,31.57) \\
1.71(0.18,16.65) \\
6.82(0.70,66.90)\end{array}$ & $\begin{array}{l}- \\
0.271 \\
0.642 \\
0.099\end{array}$ \\
\hline $\begin{array}{l}\text { Number of medications taken, } \mathbf{n} \text { (\% } \\
\geq 7 \\
4-6 \\
1-3\end{array}$ & $\begin{array}{l}25(89.3) \\
47(83.9) \\
15(78.9)\end{array}$ & $\begin{array}{l}3(10.7) \\
9(16.1) \\
4(21.1)\end{array}$ & $\begin{array}{l}1 \\
1.60(0.40,6.43) \\
2.22(0.44,11.32)\end{array}$ & $\begin{array}{l}- \\
0.511 \\
0.336\end{array}$ \\
\hline $\begin{array}{l}\text { Most recent HbA1C level, \%, } \mathbf{n}(\%) \\
>7.5 \\
\leq 7.5\end{array}$ & $\begin{array}{l}39(84.8) \\
48(84.2)\end{array}$ & $\begin{array}{l}7(15.2) \\
9(15.8)\end{array}$ & $\begin{array}{l}1 \\
1.05(0.36,3.06)\end{array}$ & $\overline{-}-936$ \\
\hline
\end{tabular}

$\mathrm{OR}^{*}$, odds ratio; $\mathrm{Cl}+$, confidence interval; $\mathrm{SD} \ddagger$, standard deviation; T2DM§, type 2 diabetes mellitus.

monitoring the effectiveness of diabetes management in collaboration with other healthcare providers.

As patient education programs, including the DMTAC and pharmacy-based counseling, have long been implemented in the public health centers across Malaysia to support patient participation in diseases management since the last decade, the majority of the participants in the current study were found to have adequate self-care behaviors. Nonetheless, it is noteworthy that the prevalence of inadequate self-behaviors is still relatively high as compared with a similar study, which reported a $6 \%$ prevalence in western urban China. ${ }^{[17]}$ In particular, among the four subscales assessed in the current study, the mean scores for the "Physical Activity" and "Diet Control" were lower than those of the other two subscales. This is consistent with the previous findings, ${ }^{[18,19]}$ suggesting that the lack of physical activity and poor diet control in patients still remain the major challenges in the management of T2DM in Malaysia. Hence, besides ensuring medication adherence among diabetic patients, continuous efforts should be made by pharmacists to determine specifically how an individual would meet the recommended lifestyle modification.

Furthermore, in parallel with the findings of a number of studies, ${ }^{[20-22]}$ it is noted that disease duration of the patients was a significant predictor of the level of self-care behaviors. Generally, the patients with disease duration less than ten years were found more likely to have inadequate selfcare behaviors. Within this context, Jackson et al. suggested that a longer disease duration provides more opportunities for patients to be exposed to diabetes-related information, which is essential to strengthen their disease management skills. ${ }^{[21]}$ Additionally, they might have experienced complications, which propelled them to better self-care behaviors. Thus, in order to delay the disease progression, it is imperative for pharmacists to intensify education on self-care, particularly among those who are newly diagnosed with T2DM.

Besides, notwithstanding that the majority of the participants had adequate self-care behaviors, approximately $45 \%$ of them were still found to perpetuate suboptimal glycemic control, indicated by a HbA1C level above $7.5 \%$. A similar trend was also observed in a UK study, in which many diabetic patients were shown to have persistent $\mathrm{HbA} 1 \mathrm{C}$ elevations despite standard diabetes management. ${ }^{[23]}$ Aside from that, numerous studies have confirmed that increased $\mathrm{HbA} 1 \mathrm{C}$ levels, especially above $7.5 \%$, are strongly associated with increased risks of cardiovascular complications and all-cause death. ${ }^{[24]}$ Accordingly, further investigation into the factors associated with persistent poorly-controlled T2DM in Malaysia is warranted.

The current study had several limitations. First, it was a single-center study, which only included diabetic patients actively followed up at a public tertiary care center. Therefore, the prevalence of inadequate selfcare behaviors might be underestimated, as the participants were likely to have better awareness of their health conditions and treatment in general. Apart from that, the assessment of self-care behaviors was based solely on self-reporting by the participants, and the data could be affected by bias arising from social desirability or selective recall. ${ }^{[2]}$

\section{CONCLUSION}

The findings imply that a noticeable proportion of patients with T2DM in Malaysia had inadequate self-care behaviors. In addition, increased disease duration was confirmed to be significantly associated with improved self- 


\section{Ang, et al.: Study about Self-Care Behaviors among Diabetic Patients}

care behaviors. As efforts have been made to broaden the scope of pharmacy practice, especially in the public health sector across Malaysia, the current study suggests a more active role for hospital pharmacists in improving the management of patients with T2DM.

\section{ACKNOWLEDGEMENT}

We would like to thank the Director General of Health, Malaysia, for his permission to publish the findings from this study. We also acknowledge the guidance and support given by Dr. Arvinder Singh HS and Wei-Yin Lim (Pharmacist), research officers from Clinical Research Centre, Raja Permaisuri Bainun Hospital, Malaysia. We wish to thank Dr. Andreas Schmitt for the permission to translate and use the DSMQ in the current study.

\section{CONFLICT OF INTEREST}

The authors declare no conflict of interest.

\section{REFERENCES}

1. Seuring T, Archangelidi O, Suhrcke M. The Economic Costs of Type 2 Diabetes: A Global Systematic Review. PharmacoEconomics. 2015;33(8):811-31.

2. NCD-RisC. Worldwide trends in diabetes since 1980: A pooled analysis of 751 population-based studies with 4.4 million participants. Lancet. 2016;387(10027):1513-30.

3. Wan Nazaimoon WM, Md Isa SH, Wan Mohamad WB, Khir AS, Kamaruddin NA, Kamarul IM, et al. Prevalence of diabetes in Malaysia and usefulness of $\mathrm{HbA1C}$ as a diagnostic criterion. Diabetic Med. 2013;30(7):825-8.

4. World Health Organization. Country and regional data on diabetes. 2016. Available from: http://www.who.int/diabetes/facts/world_figures/en/index6.html.

5. Zhang $P$, Zhang X, Brown J, Vistisen D, Sicree R, Shaw J, et al. Global healthcare expenditure on diabetes for 2010 and 2030. Diabetes Res Clini Pract. 2010;87(3):293-301.

6. Smith KJ, Rabasa-Lhoret R, Strychar I, Karelis AD, Clyde M, Levasseur J, et al. Good vs. Poor self-rated diabetes control: Differences in cardiovascular risk and self-care activities. Exp clini Endo Diabetes. 2014;122(4):236-9.

7. Shrivastava SR, Shrivastava PS, Ramasamy J. Role of self-care in management of diabetes mellitus. J Diabetes Metab Disord. 2013;12(1):14.

8. Smith M. Pharmacist's role in improving diabetes medication management. J Diabetes Sci and Technol. 2009;3(1):175-9.

9. Lim P, Lim K. Evaluation of a pharmacist-managed diabetes medication therapy adherenece clinic. Pharmacy Practice (Granada). 2010;8(4):250-4.

10. Bakar ZA, Fahrni ML, Khan TM. Patient satisfaction and medication adherence assessment amongst patients at the diabetes medication therapy adherence clinic. Diabetes and metabolic syndrome. 2016;10(2):S139-43.
11. Raja Permaisuri Bainun H. Hospital's profile. 2017. [cited 201731 May]. Available from: http://hrpb.moh.gov.my/v2/index.php/en/mengenai-kami/profil-hospital.

12. Schmitt A, Gahr A, Hermanns N, Kulzer B, Huber J, Haak T. The diabetes self-management questionnaire (DSMQ): Dvelopment and evaluation of an instrument to assess diabetes self-care activities associated with glycaemic control. Health and Quality of Life Outcomes. 2013;11(138):1-14.

13. Beaton DE, Bombardier C, Guillemin F, Ferraz MB. Guidelines for the process of cross-cultural adaptation of self-report measures. Spine (Phila Pa 1976). 2000;25(24):3186-91.

14. Pfeiffer AF, Klein HH. The treatment of type 2 diabetes. Deutsches Arzteblatt international. 2014;111(5):69-81.

15. Schmitt A, Hermanns N, Kulzer B, Reimer A, Schall S, Haak T. The diabetes selfmanagement questionnaire (DSMQ) can detect inadequate self-care behaviour and help identify patients at risk of a negative diabetes prognosis. 50th EASD Annual Meeting; 15-19 September 2014; Vienna Austria. 2014.

16. Naing L, Winn T, Rusli BN. Practical issues in calculating the sample size for prevalence studies. Arch Orofacial Sci. 2006;1:9-14.

17. Huang M, Zhao R, Li S, Jiang X. Self-management behavior in patients with type 2 diabetes: a cross-sectional survey in western urban China. PloS one. 2014;9(4):e95138.

18. Tan M, Magarey J. Self-care practices of Malaysian adults with diabetes and suboptimal glycaemic control. Patient education and counseling. 2008;72(2):252-67.

19. Zaki NF, Sulaiman AS, Gillani WS. Clinical evaluation of Dyslipidemia among type II diabetic patients at Public hospital Penang, Malaysia. Int Archi Med. 2010;3(1):34.

20. Tol A, Shojaeezadeh D, Eslami A, Alhani F, Mohajeritehrani M, Baghbanian A, et al. Evaluation of self-care practices and relative components among type 2 diabetic patients. J Edu and Health Promotion. 2012;1:19.

21. Jackson IL, Adibe MO, Okonta MJ, Ukwe CV. Knowledge of self-care among type 2 diabetes patients in two states of Nigeria. Pharmacy Practice. 2014;12(3):404.

22. T'ang J, Chan C, Chan N, Ng C, Tse K, Lau L. A survey of elderly diabetic patients attending a community clinic in Hong Kong. Patient Edu Counseling. 1999;36(3):259-70.

23. Crowley MJ, Holleman R, Klamerus ML, Bosworth HB, Edelman D, Heisler M. Factors associated with persistent poorly controlled diabetes mellitus: clues to improving management in patients with resistant poor control. Chronic illness. 2014;10(4):291-302.

24. Chen YY, Lin YJ, Chong E, Chen PC, Chao TF, Chen SA, et al. The impact of diabetes mellitus and corresponding $\mathrm{HbA} 1 \mathrm{c}$ levels on the future risks of cardiovascular disease and mortality: a representative cohort study in Taiwan. PloS one. 2015;10(4):e0123116.

25. Althubaiti A. Information bias in health research: Definition, pitfalls, and adjustment methods. J Multidiscip Healt. 2016;9:211-7. 